\title{
Reforms introduced by Hokkaido University
}

\author{
Valentina Akimova, Sargylana Atlasova*, Tamara Kurchatova, Marianna Markova, and Ksenia Ershova
}

North-Eastern Federal University, 58 Belinsky str., Yakutsk, 677027, Russia

\begin{abstract}
The coexistence of new technologies and cultural traditions allows search and finding related answers to the latest questions in educational development. Reforming the higher education system passes without breaches of national identity and demonstrates the raised efficiency of reforms. In this paper issues in higher education reforming have been considered by the example of Hokkaido University. The Management Staff of the university got an expanded authority; however, modernization of the higher education system has links with the international exchange system. The Hokkaido Short-Term exchange program has been provided since October, 1997. In 2014 Ammosov North-Eastern Federal University (Yakutsk) and the University of Hokkaido signed the Protocol for establishing an intent to enhance promotion and development of new Master Degree Programs, applying resources of Russia and Japan. Thus, Hokkaido University has changed a model - based on following standards of leading countriesand started attempts to rethink a mission of its own. The Management staff set middle-, long-term goals, taking into account the expert community judgments but the internalization strategy surely is an important link.
\end{abstract}

\section{Introduction}

Study of the Japanese educational system is of great interest to Russian pedagogical science and practice. Modern technologies and folk traditions co-existing in this country allow us to search for and find answers to topical questions about the relationship between the standard of living and the quality of education in the modern world.

The Japanese government announced an ambitious plan to include 13 universities into the ranking of the 100 best universities in the world. Currently, there is Tokyo University and Kyoto University on the list of the top 100 world universities [1].

Over the past 15 years of permanent reforms, the Japanese educational system has achieved remarkable results. For example, 8 scientists who specializes in the field of physics, 5 researchers in the field of chemistry and 3 researchers in medicine and physiology have been awarded the Nobel Prize [2]. Winnings of Japanese students successfully compete in international assessment tests [3]. Hence, there is importance of investigating the nature of learning in Japan at the present stage.

\section{Materials and methods}

The Japanese teaching-studying-learning process has always allured the interest of researchers. Professor S. Ch. Lim has dedicated her monograph "History of Education in Japan" to innovations within the period of capitalist modernization at the end of the XIX century
[4]. She has analyzed challenges faced by the country, for instance, the teacher shortages, problems of democratization, significance of the first universities. The author of the thesis "The Japanese society: exploring new paradigms for the development in 1970-80s" A.A. Nikolaev has devoted a chapter to the education system and its connections to the social, cultural and political changes [5]. The research work "The main characteristics of education system reformation in Japan (in the late XX - early XXI century)" by E.G. Zinurova has been concentrated on problem-solving and continuous improvement of the higher education quality at the beginning of the XXI century [6]. A.E. Kochkina, as an author of the research project "Forming the moral character of the person in the traditional method of teaching (by the example of Japan)", has noted the historical patterns of moral pedagogy in Japanese schools and assessed their efficiency [7]. In the paper written by T.V. Brel and S.S. Shchevelev, researchers considered changing the historical context and unchanging features of Japanese pedagogy, which have helped to build a modern productive society [8].

The topic of education revision in Japan perpetually has been explored by western investigators since 1945 . Ronald F. Dore studied substantially the education evolving in Tokugawa Japan [9]. Robert King Hall highlighted principles of teaching and renewal organization structure in the post war period in his research work "Education for a new Japan" [10]. Research scientists Gary Hoichi Tsuchimochi accentuated a crucial role of the United States in establishing the democratic educational institutions after the World War II [11].

\footnotetext{
Corresponding author: $\underline{\text { ss.atlasova@s-vfu.ru }}$
} 
Oriental historiography is represented by $\mathrm{M}$. Tsujimoto and Y. Yamasaki, whose monograph "History of Education in Japan (1600-2000)" shifted the emphasis to the Meiji revolution, as a heyday of Japanese democratization [12]. The author of the world famous monograph "Higher Education in Japan: Its Take-Off and Crash" Michio Nagai identified and analyzed the causes of problems in education system in the early 1970s [13]. In this survey, Dr. Nagai adhered a critical approach to the results of permanent reforming and helped to track the vector of the amendments in 1970s. M. Aso and I. Amano in their mutual research work "Education and Modernization of Japan" ascertained problems, which are worth paying attention to, for the next generation of reformers [14]. T. Kariya considered the impact of globalization on the higher education system in "Education reform and social class in Japan", which is facilitated of growing inequality and led to the quite contradictory results. In this survey the author used empirical research methods [15]. Consequently, most research findings are unveiling the general characteristics of the Japanese education system.

As of 2015, there were 779 universities and colleges accredited across Japan - 86 national universities, 89 municipal state universities and 604 private universities, of which Keio, Waseda, Tokai became the top private universities [16]. Japanese national universities comprise the University of Tokyo, Osaka University, Kyoto University, Tohoku University in Sendai, Hokkaido University in Sapporo. As a participant of the world class university program, Hokkaido University designed the plan of its own, timed to coincide with the $150^{\text {th }}$ university anniversary in 2026.

\section{Results and discussion}

Japan has quickly modernized the higher education system. These innovations have accomplished without breaching the foundations of the national mentality and the results have proved the high effectiveness of pedagogical reforms. In this paper the authors considered the problem of reforming higher education by the example of the University of Hokkaido. This university, located in Sapporo, has developed strong links with North-Eastern Federal University (NEFU, Yakutsk city). Hokkaido University mainly focuses on natural science, placing an emphasis on basic research.

Currently, more than 18,500 students are studying at 30 divisions and departments of Hokkaido University, one third of whom are residents of other prefectures or international students, and two thirds are Hokkaido natives [17]. As well as in other national universities, the organizational structure has been preserved since its foundation, namely: the Faculty of Humanities (Languages, Literature, History, Philosophy, Religion, Psychology) and the Faculty of Law (Law course, Public Administration, Political Science, etc.), the Faculty of Education, the Faculty of Engineering, the Faculty of Economics and Business Administration, the Faculty of Science (Mathematics, Physics, Chemistry, Biological Sciences, the Earth and Planetary Sciences), the Faculty of Medicine, Faculty of Pharmaceutical Sciences, the Faculty of Veterinary Medicine, Fisheries Sciences, Agriculture. Separately, it is worth noting Faculties of Medicine Pharmaceutical Sciences. Relatively recently, Department of Electronics and Information has been established with the Faculty of Engineering.

The Board of Executives is represented by Vice Presidents, Executive Directors and invited Advisors of the President (Professors) and reports directly to the President [19]. The Administrative Council assumes the responsibility for managing, while the Education and Research Council manages the educational process. The Administrative Council means the board comprised of the Director for Sustainable Development, Vice Mayor of Sapporo, General Director of Hokkaido Bureau of Economy, Trade and Industry, Vice Governor of Hokkaido, Presidents and Representative Directors of companies, internal auditors.

Structural reforms have changed the status of the president, who began to perform the functions of a top manager. The objective of the management development process is to improve from the previous bottom-up style to the top-down style in order to accelerate the decision-making process. The president is granted the authority to propose directors, accept or reject the budget and staffing of the university corporation. The President exercises his power in relation to Research Centers, Undergraduate schools, Graduate schools, Faculties and the administrative staff. Upon completion of the term, the President and Directors are required to leave their serving at university.

Along with the President and the Board of Executives and Administration, the organization has a staff comprise Deans and Directors, involving the Director of Hokkaido University Hospital, the Director of Institute of Low Temperature Science, Director, Director of Center for Ainu and Indigenous Studies and heads of other Joint Facilities and Research Institutes.

Besides, the off-campus membership represented by Director of the Hokkaido Bureau of Economics, Trade and Industry, Consultant from Nippon Light Metal Holdings, Professor of the Kyoto University, CEO of Otsuka Holdings, a special advisor from Meidi-ya, the head of Hokkaido Electric Power, Deputy Director of Japan Science and Technology Agency and other advisors among, authorities, the business field and the higher educational establishment. The executive board has wide powers in finance and management, including the appointment of instructors, the issue of remuneration academics or determining the duration of an employment contracts. Consequently, the professional organization of the university amalgamates administrators comprehended experts with a management experience and competences.

Hokkaido University also works closely with research centers and institutes and promotes the research activity on the island. The Institute for Chemical Reaction Design and Discovery, the Institute of Low Temperature Science, the Research Institute for Electronic Science, the Institute for Catalysis, the 
Center for Human-Nature, Artificial Intelligence, and Neuroscience, Artificial Intelligence and Neuroscience, the Global Research Center for Food and Medical Innovation, the Center for Innovation and Business Promotion, the Slavic-Eurasian Research Center, the Information Initiative Center, the Research Center for Zoonosis Control, the Central Institute of Isotope Science, the Research Center for Integrated Quantum Electronics, the Center for Advanced Tourism Studies, the Center for Ainu and Indigenous Studies, the Center for Environmental and Health Sciences, the Arctic Research Center, the Research and Education Center for Brain Science, Center for Language Learning (in particular Russian), the Archaeological Research Center are located on the island. The University Research Centers are constructed throughout Hokkaido, encompassing the Botanic Garden, Observatories and Planetariums, Fish Aquaculture Research Food Science Platform, hydro- and volcano logical stations, livestock farms and experimental forests and agricultural lands, several dozen different laboratories.

Sapporo houses Hokkaido University Museum, University archives, two medical centers and hospital beds per a thousand people and the library collection. The size of the library holdings exceeds 3 million items of books and magazines.

It is noticeable that Japanese universities gain substantial investments from private sector. Recent decades have seen considerable progress in strengthening the potential of $R \& D$, in consequence of which universities should have strengthened in the growth of scientific publications, interaction between business and academia, scientific and technical capacity. In addition, the institutions had to implement principles of scientific management and promote the introduction of developments.

It should be pointed out that Hokkaido University invited partners in order to cooperate in the field of research, such as Hitachi, Mitsubishi, North Pacific Bank and amongst others industrial and financial companies [17]. With benefit of financial participation of the private sector, the Creative Research Institution was built for examining the impact of nanobiotechnology, pharmaceutical, chemistry and engineering researches. They also promote glaciologycal researches and indigenous studies of the Ainu, veterinary medicine studies and researches in the field of fisheries. The Institute of Low Temperatures is no less known division of the university, which explores temperatures in the high atmosphere, in sea depths. The Slavic-Eurasian Research Center, which is part of the Faculty of Law, assists in the review of the Sea of Okhotsk marine ecosystem [17].

Definitely, current updates in the Japanese higher education system are closely linked with International Student Exchange. In the 1990s, when an active international exchange has begun, there was concern about the imbalance between Japanese students studying abroad and foreign students coming to Japan [20]. This anxiety occurred because of educational programs in English have been developed just in a few universities. However, demand for students who wanted to study
1-2 semester in Japan, while earning credits at their universities, was constantly growing. When programs have appeared, the purpose of which was not only to allow you to immerse students in Japanese culture and take courses at a Japanese university, but also to diversify educational methods for the purpose of internalizing teachers and students [21].

In 2014, the North-Eastern Federal University and Hokkaido University signed the protocol for establishing intent to enhance promotion and development of new Master programs, applying the resources of Russia and Japan. Undergraduate and graduate students of both universities participate in the work of International summer schools, such as "Taiga Ecosystem in the Cryolithozone: the Role of Permafrost in Global Climate Change" which have affirmed their efficiency. Students of the school will have an excellent opportunity to the development of international scientific cooperation. Russian and Japanese students investigate the water exchange process of forest ecosystems, carry out an inventory of frozen forest, explore the areas of leaf indices of plants in various types of forest.

Thereby, it should be noted that the Hokkaido University Short-Term Student Exchange Program (HUSTEP) has been operating since 1997, as project has been created for co-operation with affiliated universities and offered an internship lasting for 1 year. Participants in the program had an opportunity to learn Japanese language, register for a quite wide range of courses in English. The academic year in Japan comprises of 2 semesters (that is two equal parts of 14 weeks): the first term - from October to February and the second term - from April to August. Spring holidays for students begin in mid-February and in early April, which does not quite correspond to the North American and European academic calendar. Many participants from North-Eastern Federal University pointed out advantages of the HUSTEP program.

Foreign students are encouraged to choose the minimum courses required in English to obtain a visa and competitive advantage. Before the beginning of semester, academic staff make presentations to reveal the content of the course (some subjects require a certain professional skills). At first, Japanese students were not allowed to attend classes for foreigners, but then the restriction was lifted. As a part of the program, students take part in cultural classes, which are held at the end of the term and lasts $1-2$ weeks. These classes' purpose is to give a basic introduction to calligraphy, bonsai art, aikido, the Japanese vargan, the tea ceremony (sado). These classes are optional, as a rule, and students also prefer making a trip at the end of the term.

Students, whose applications are accepted, have an opportunity to obtain a scholarship conducted by the Japan International Student Support Organization [20]. JASSO is the independent administrative agency affiliated with the Ministry of Education, cultures, sport, sciences and technologies of Japan (MEXT). The scholarship was a project of the Ministry of Education 
in order to support the promotion of international cooperation and contribute to the growth of international students. The monthly scholarship payment is 80,000 yen, which fully covers the living in rental apartments of the student accommodation and daily expenses. These payments are accrued monthly after students arrive in Japan. In the year when the program was launched, there was no competitive process of participants and everyone who sent applications received scholarships, however, contemporary candidates have to undergo competitive selection. One of the principal aims of HUSTEP is to improve the quality of the program, for which administrative coordinators participant feedback upon completion of the internship.

Commenced in 2008 by the Japanese Ministry of Education, Culture, Sports, Science and Technology, the campaign aims to internationalize higher education in Japan. Establishing the Global 30 Project, the government of Japan conjectured it would facilitate the development of Japan (on conditions of aging society). This project, providing a variety of opportunities for international students from affiliated universities, attracts motivated students all over the world [22].

In 2016 the initial government plan has been enlarged, in particular 37 universities were suggested to work out at the world-class strategy. The Ministry of Education, Culture, Sports, Science and Technology (MEXT) determined targets needed for effecting the purpose by 2024 and included Tokyo University, Osaka University, Tohoku University, Kyoto University, Waseda University, Nagoya University, Hokkaido University into the «Top Global Universities (20142023)» [23]. The Ministry prioritized the following tasks: developing the existing degree programs, designing new classes in English, stimulating the growth of student mobility, overcoming the language barrier through internalization of teaching and administrative staff, arranging international university summits for the discussions of research problems, providing an opportunity to apply a scholarship, granting the annual financial support at the amount of $200-400$ million yen during 5 years, popularization of Japanese culture and language abroad by means of «The Japan Foundation» activity, establishing the assistance services for foreign students in Japan. There were certain expectations that student mobility rate would rise and attained the quantity of 300 thousand students by 2020 (10\% of total amount). However, the COVID19 has slightly destroyed this potential scenario. Adapting the new reality, both the Hokkaido University and other institutions had closed down global campuses, shifted to online learning.

\section{Conclusion}

To sum up, this project aims to heighten an international competitiveness of higher education system of Japan. Though carrying out current targets, it will be able to bring a revenue to the universities, operated on a self- supporting, push scientific research work toward worldleading level

For the first few years, most of instructors were questioned whether to offer their course in English, and as an incentive they were offered bonuses for conducting the course in English. Further, with an increase in the number of professors involved in HUSTEP Program, rotation has increased (5-6 professors could teach the same course) [20]. Moreover, surveys were conducted among students on which subjects should be introduced, and during the public discussion many courses were added to the list of classes.

It can be argued that the number of participating countries is gradually growing. For the first year, only 2 foreign countries participated in an international exchange program. Subsequently, the development of international cooperation and partnership with students from 25 countries of the Americas, Europe, Africa, Oceania and Asia were attained by 2016. The expansion of geography suggests that a positive image and the brand recognition of Hokkaido University have been set up. It is also noted that HUSTEP has a positive impact on the faculty members, the administration staff of the University and Japanese students.

Besides, MJSP (Modern Japanese Studies Program) offers to obtain a bachelor's degree in Hokkaido University [18]. According to the requirements, initially, students learn Japanese language on the intensive six months courses, then they attend joint classes with Japanese students to secure a bachelor degree. MJSP gives a complete immersion in the language environment and at the same time students study history, political science, culture and sociology. The application requires a School Certificate and an English Certificate.

The established academic networks linking universities around the world brought universities closer together in terms of cooperation in the field of education and scientific research, and increased international competition. Hokkaido University has changed the model of following and imitating other leading countries to initiatives to create a mission for its university. The university management adopts mediumand long-term strategies, taking into account the reaction of the expert community, but the internationalization strategy remains as the central point.

\section{References}

1. Official website of The Times Higher Education journal. Retrieved from: https://www.timeshighereducation.com/worlduniversity-rankings

2. The Official Website of the Nobel Prize. Retrieved from: https://www.nobelprize.org/

3. Nippon.com. Retrieved from: https://www.nippon.com/ru/genre/society/110624/

4. S. Ch. Lim, History of Education in Japan ((in the late XIX -early XX century). Moscow: 
Institute of Oriental Studies, Russian Academy of Sciences, (2000)

5. A. A. Nikolaev The Japanese society: exploring new paradigms for the development in 1970-80s: doctor's these. RUDN. Moscow (1999)

6. E.G. Zinurova The main characteristics of education system reformation in Japan (in the late $X X$-early XXI century): doctor's thesis. KGPU. Kazan. (2004)

7. A.E. Kochkina Forming the moral character of the person in the traditional method of teaching (on the example of Japan): doctor's thesis. KChGU. Karachaevsk. (2005)

8. T.V. Brel, S.S. Shchevelev Japanese education system reformation in the Meiji Era. Culture of People in the Circum-Pontic region. 248, 98-100 (2012)

9. F. Ronald Dore Education in Tokugawa Japan. Univ. of California Press. (1965)

10. K. Robert Hall Education for a new Japan. New Haven: Yale University Press, (1949)

11. H. Gary Tsuchimochi Education Reform in Postwar Japan: The 1946 U.S. Education Mission. University of Tokyo Press, (1993)

12. M. Tsujimoto, Y. Yamasaki_The History of Education in Japan (1600 - 2000). Routledge Studies in Educational History and Development in Asia. (2017)

13. M .Nagai Higher Education in Japan: Its TakeOff and Crash. Tokyo: Univ. of Tokyo Press. p. (1971)

14. M. Aso, I. Amano Education and Modernization of Japan. Challenges in Modern Japan. Education in Japan. Journal. XI, 18. (1974)

15. T. Kariya Education reform and social class in Japan. New York: Routledge. (2012)

16. L .P. Verevkin The higher education system in Japan. Mat. of the Inter. Science Conf., April 2324. - Sankt-Petersburg, vol. 1, p. 12. (2019)

17. D.B. Pavlov The Hokkaido University («Boys, be ambitious!»). Rus. Journal of Japanese Studies, 1, 70-87. (2010)

18. The Official Web-site of Hokkaido University. Retrieved from: https://www.hokudai.ac.jp/introduction/gov/

19. R. Yamada, Impact of Higher Education Policy on Private Universities in Japan: Analysis of governance and educational reform through survey responses. Higher Education Forum. 15, 27. (2018)

20. P. Firkola Globalization in Japanese Universities: A Case Study of HUSTEP. Journal of Higher Education -Higher Education and Lifelong Learning, 24, 3. (2017)

21. W. Manakul Role of English in Internationalization of Higher Education: The Case of the Graduate School of Engineering, Hokkaido University Higher Education and Lifelong Learning, 15, 160. (2007)

22. I. I. Gushchin Modern processes of internalization in Japan. Vestnik MGOU. Series: Pedagogy, 3, 40. (2012)
23. Official Web-site of the Ministry of Education, Culture, Sports, Science and Technology of Japan. Retrieved from: https://www.mext.go.jp/a_menu/koutou/kaikak u/sekaitenkai/1360288.htm 